\title{
AUTOLOGOUS CHONDROCYTE IMPLANTATION
}

\author{
Ronald Bispo Barreto, José Ricardo Pécora, Riccardo Gomes Gobbi, Márcia Uchôa de Rezende, Gilberto luis Camanho
}

\section{ABSTRACT}

This literature review article describes the autologous chondrocyte implantation $(\mathrm{ACl})$ process - its stages, clinical indications, surgical technique, laboratory protocol, rehabilitation and clinical outcomes. Since 1994, when the ACl was described for the first time, the procedure has improved to become one of the most important surgical alternatives for the treatment of chondral lesions of the knee.

Keywords: Knee trauma. Chondrocytes. Autologous transplant. Humans. Cell culture.

Citation: Barreto RB, Pécora JR, Gobbi RG, Rezende MU, Camanho GL. Autologous chondrocyte implantation. Acta Ortop Bras. [online]. 2011; 19(4):219-25. Available from URL: http://www.scielo.br/aob.

\section{INTRODUCTION}

Hyaline cartilage covers joint surfaces and plays an important role in reducing friction and mechanical loading on synovial joints such as the knee. As it is not vascularized, this tissue has a very limited healing capacity. For the same reason, there is no inflammatory response to the tissue damage. Hence there is no invasion of macrophages that remove the devitalized tissues, and no cell migration with the ability to repair the damaged area. ${ }^{1,2}$ These lesions do not heal and may eventually progress to arthrosis. This evolutionary process is regulated, both by chemical mediators that mix with the synovial liquid such as Caspases, Interleukin-1 and -6 and Nitric Oxide (enzymatic degradation) ${ }^{3,4}$, and by repetitive micro-trauma (mechanical overload) $)^{5,6}$ and the blocking of some of these substances can result in a clinical improvement of the joint with the lesion in the cartilage, as demonstrated by Rezende et al. ${ }^{7}$

Excellent clinical results can be obtained among elderly patients with severe arthrosis when they are treated with total knee arthroplasty. In young patients, treatment of chondral defects of the knee is not yet standardized, despite some attempts to this end. ${ }^{8,9}$ The therapeutic alternatives include simple joint washing with or without debridement, aimed at removing chemical mediators and free bodies that degrade the cartilage and cause pain ${ }^{10}$; perforations, microfractures and abrasions, which regenerate the joint surface with scar tissue similar to hyaline cartilage (fibrocartilage), from medullary mesenchymal cells ${ }^{11}$; mosaicplasty (autologous osteochondral transplantation) and autologous chondrocyte transplantation, also known as autologous cartilage implantation (ACl). ${ }^{10}$

Buckwalter ${ }^{1}$ describes the joint cartilage inside a functional unit with biological and mechanical properties. This model is composed of the different layers of chondral cells and by the subchondral cortical and spongy bones. Techniques that interfere with the subchondral bone plate (perforations, microfractures and mosaicplasty) may even reestablish the joint surface, but do not restore the mechanical property of the cartilage, especially the impact absorption function. The $\mathrm{ACl}$ technique has shown biological and mechanical advantages in comparison to the others, since besides preserving the subchondral bone support, it repairs the chondral defect with tissue similar to that of the hyaline cartilage.

Since 1994, when Brittberg et al. ${ }^{12}$ described the ACI technique for the treatment of chondral knee lesions, many surgeons have begun to study the subject. Nowadays, there are many modifications of the technique, from the first generation to the second and third chondrocyte implant generations. ${ }^{13-17}$ This procedure has become one of the most important surgical alternatives for the treatment of chondral lesions of the knee, and its use has extended to the treatment of chondral lesions in other joints such as the ankle, shoulder, hip and wrist. ${ }^{18-22}$

\section{INDICATIONS}

The ideal patient for autologous chondrocyte implantation presents a chondral lesion affecting the total thickness (Outerbridge $^{23}$ or International Cartilage Repair Society [ICRS ${ }^{24}$ degree III and IV) or osteochondral defect surrounded by normal and healthy cartilage in one knee without other lesions. The ideal lesion is an exception rather than the rule, since many knee lesions occur, simultaneously, in some degree of association with other pathologies. These combined lesions often present

All the authors declare that there is no potential conflict of interest referring to this article.

Orthopedics and Traumatology Institute of Hospital das Clínicas da Faculdade de Medicina da Universidade de São Paulo

Study conducted at LIM 41 - Laboratory of Medical Investigation of the Musculoskeletal System of the Department of Orthopedics and Traumatology of Faculdade de Medicina da Universidade de Sáo Paulo.

Mailing address: Riccardo Gomes Gobbi Rua Dr. Ovídio Pires de Campos, 333, Cerqueira César. CEP 05403-000 - São Paulo/SP. Brazil.

E-mail: gobbi85@bol.com.br

Article received on 6/18/2010 and approved on 9/12/10.

Acta Ortop Bras. 2011;19(4): 219-25 
a rim of cartilage of doubtful quality around their circumference, thus compromising the chondrocyte implantation. ${ }^{25,26}$

$\mathrm{ACl}$ should be considered second-line treatment for chondral defects $\left(<2 \mathrm{~cm}^{2}\right)$, and should only be used when other, simpler techniques such as microfractures fail. On the other hand, if the defects are larger than $2 \mathrm{~cm}^{2}, \mathrm{ACl}$ should be used as the treatment of choice. The defect should be located on the femoral or patellar joint surface and should be accessible by means of arthrotomy. The definitive indication for using ACl should only be considered during arthroscopic assessment. This procedure is the best determinant of the location, depth and size of the defect, besides evaluating the quality of the surrounding cartilage and the state of the chondral surface opposite the lesion. ${ }^{25,26}$ Patients should have their deformities (varus and valgus) and any ligament instability (anteroposterior, collateral and patellar) corrected before the $\mathrm{ACl}$ procedure, due to the risk of treatment failure.

\section{CONTRAINDICATIONS}

$\mathrm{ACl}$ is not indicated for patients with severe arthrosis or in the presence of bone-on-bone bipolar lesions. For this reason, the physical examination should be supplemented by obtaining a radiograph of the knee to exclude advanced degenerative joint disease. Other contraindications are rheumatoid arthritis or other active autoimmune disease of the connective tissue and patient with malignant neoplasia. ${ }^{25}$

\section{CLINICAL EVALUATION}

The evaluation of the patient with chondral or osteochondral defect begins with the history of symptoms (joint effusion, joint block and pain) and of trauma (old sprains can be the cause of the problem). Family history (osteochondritis, metabolic disorders etc.) and previous surgeries (meniscal resection, ligament reconstruction etc.) are important due to the subsequent damage to the cartilage. ${ }^{9}$

The physical examination should be focused on the following aspects: valgus or varus deformities, patellar alignment or instability, ligament instability (anterior, posterior and lateral), pain on palpation, effusion, crepitation, range of motion and joint blocks. The radiographic evaluation is also crucial. For this reason we take conventional radiographs of the knee (AP, lateral and axial view of the patella). Other special views are necessary to obtain information on the alignment of the lower limbs (panoramic radiograph of the patient standing and with knees extended) and of possible signs of degenerative osteoarthritis (Rosenberg's AP). ${ }^{27}$

Magnetic Resonance (MR) is a very useful tool in the diagnosis of chondral lesion. High resolution images obtained by modern devices ( 1.5 or 3 Tesla) help surgeons in the preoperative planning, providing detailed information about the chondral defect and the adjacent subchondral structure. ${ }^{9,28}$

$\mathrm{ACl}$ candidates should undergo an arthroscopic evaluation, an essential stage for preoperative planning. MR images do not yet have sufficient sensitivity or specificity to evaluate certain chondral lesions. In addition, only arthroscopy enables direct viewing and palpation of the joint cartilage, and thus allows us to diagnosis changes to its consistency and possible partial delamination. Only arthroscopic examination of the knee makes it possible to exactly determine the size and depth of the chondral defect, and the quality of the surrounding cartilage..$^{9,25}$

\section{SURGICAL TECHNIQUE}

This is a procedure carried out in two stages. Initially, a biopsy is taken from the cartilage and is sent for chondrocyte culturing (cell proliferation) in the laboratory. Cell implantation is performed in the following stage, consisting of arthrotomy, preparation of the chondral defect, harvesting of periosteum, hermetic fixation of periosteum over the lesion with stitches and fibrin glue, injection of chondrocyte concentrate and closing of the operative wound. (Figure 1)

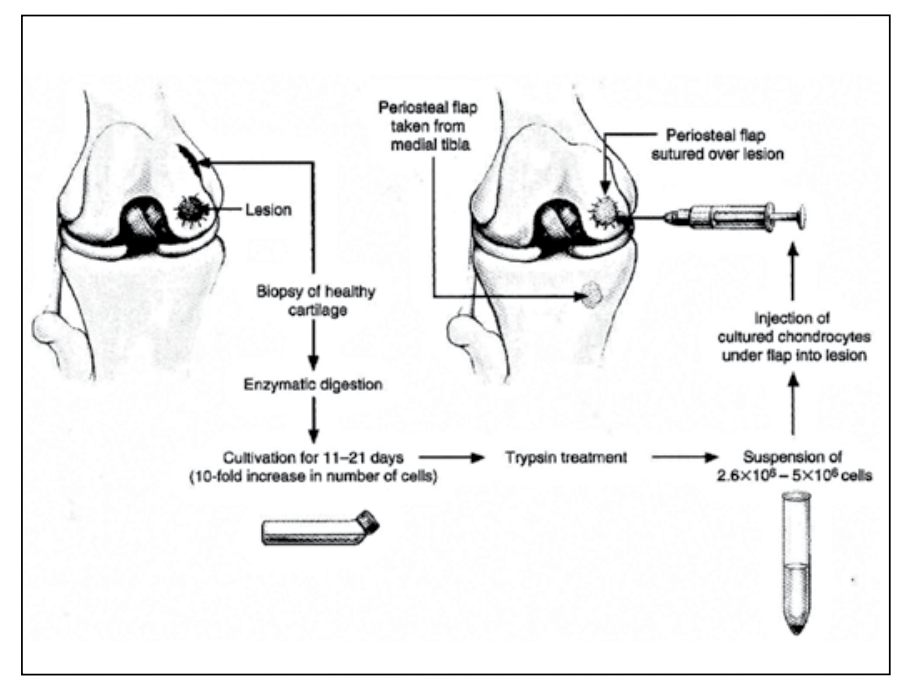

Figure 1. Diagram of the autologous chondrocyte transplantation procedure (Brittberg, 1994). ${ }^{12}$

\section{Harvesting of cartilage for cell expansion}

During the arthroscopic evaluation, and after making sure that the lesion is eligible for $\mathrm{ACl}$, the surgeon should perform delicate debridement of the lesion and remove possible free bodies and cartilage fragments from the joint. Only then should cartilage harvesting for cell expansion be performed. Meniscal lesions should be treated on this occasion, yet only after the chondral biopsy. This conduct protects the healthy cartilage from possible trauma and improves cell reproduction rates in the laboratory.

The most common sites to obtain samples of healthy cartilage are the superomedial and superolateral edges of the femoral condyles and on the lateral wall of the intercondylar notch. These are distal femoral sites that do not have load and do not articulate with the tibia or with the patella.

To harvest the cartilage, curettes or intervertebral disc biopsy tweezers are used, and three or four small cartilage fragments are obtained, with their thickness totally or partially free of subchondral bone. To achieve enzymatic digestion and adequate cell culturing, approximately 200 to $300 \mathrm{mg}$ of joint cartilage are required, corresponding to around $1 \mathrm{~cm}^{2}$. 
During this procedure, $200 \mathrm{ml}$ of venous blood should be taken from the patient. This blood is used to extract the serum to be used with the culture medium for cell proliferation.

The cartilage harvesting procedure is safe, without complications and without late symptoms at the collection harvesting sites described in literature. Adequate harvesting is essential for the success of the cell culture, and good quality of cells is necessary to obtain the best results with the procedure.

\section{In vitro cell expansion}

The main objective of in vitro manipulation of chondrocytes is to increase the number of cells. This process starts with enzymatic digestion of the extracellular matrix of the cartilage that corresponds to approximately $90 \%$ of the tissue and is formed by a dense three-dimensional network containing associated collagen and proteoglycan molecules. The controlled use of proteolytic enzymes such as hyaluronidases, collagenases and trypsin allows the degradation of the elements that form the extracellular matrix, resulting in the isolation of a suspension of viable chondrocytes from a cartilaginous fragment. ${ }^{45}$ (Figure 2A) The viability of the chondrocytes can be obtained with the use of stains, such as Trypan blue, followed by counting in a hemocytometer chamber (Neubauer counting chamber). The primary cultures are initiated with a minimum concentration of chondrocytes presenting viability above $85 \%$. Monolayer culturing should be used for the proliferation of these cells. In this system, the cells are cultivated in $25 \mathrm{~cm}^{2}$ culturing flasks with the DMEM/HAMF12 culture medium supplemented with $10 \%$ autologous serum. ${ }^{10,11}$ The autologous serum is used as a source of hormones and growth factors for the cultured cells. In some protocols bovine fetal serum can be us to supplement the chondrocyte cultures, as it is a richer source of these cell inducer molecules and produces more uniform results for primary cultures. The cells are kept at $37^{\circ} \mathrm{C}\left(98.6{ }^{\circ} \mathrm{F}\right)$ with $5 \% \mathrm{CO}_{2}{ }^{29}$ Under these conditions, monolayer system with medium supplementation, the chondrocytes adhere to the cell culture dishes, losing the characteristic rounded morphology and acquiring morphology typical of fibroblasts. (Figure 2B) This phenotypic alteration of the chondrocytes is characterized as cell dedifferentiation and results in cellular metabolic changes. The cells divert the preferential synthesis of collagen II, replacing it with the synthesis of collagen I, besides other alterations. ${ }^{30,31}$ Due to the morphological and functional alterations, the chondrocytes acquire proliferative capacity. ${ }^{32,33}$ (Figure 2C)

The term monolayer is used as the cells do not overlap in culture; if this occurs it gives rise to the process called contact inhibition, due to the presence of very close cells, which entails cell death. When the number of cells increases, resulting in the occupancy of the culturing flask, it is said that the monolayer is confluent (Figure 2D); at this time the cells are transferred to new flasks, in the process denominated cell replication and with the use once again of proteolytic enzymes such as trypsin. The cells are taken from the culturing flask and inoculated in new flasks, reducing the low cellular density. This maneuver allows the maintenance of the dedifferentiated state of the cell and of its proliferative capacity. The chondrocytes are kept in this monolayer culturing system for a mean period of 4 weeks, Acta Ortop Bras. 2011;19(4): 219-25
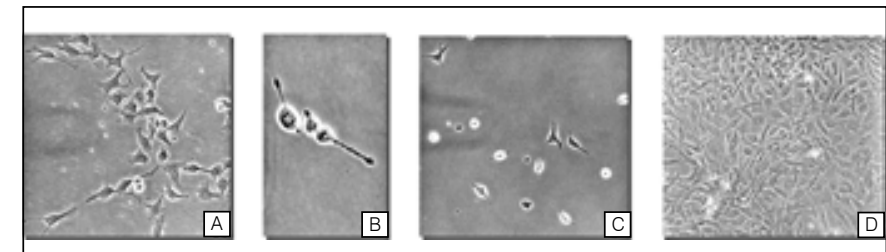

Figure 2. (A) Beginning of the primary culture of chondrocytes (3 days of culture); it is possible to observe some round cells and others initiating the process of adhesion to the substratum, with more elongated morphology (20x); (B) Formation of the chondrocyte monolayer with elongated morphology (5 days of culture) (20x); (C) Detail demonstrating two cell divisions (40x); (D) Confluent monolayer of chondrocytes with area of cell groupings and overlapping (10 days of cultuture) (10x).

in order to obtain around $10 \times 10^{6}$ cells, a concentration considered a therapeutic dose. ${ }^{11}$

The phenotypic and metabolic alteration of monolayer cultured chondrocytes is merely transitory and can be reverted by suppressing the high percentage of supplementation with the autologous or bovine fetal serum, and transferring the cells to a three-dimensional medium, either the actual cartilage or threedimensional matrixes. ${ }^{34-36}$

Nowadays there are three generations of chondrocyte cultures. In the first, the cell culture is performed as a monolayer and the cell implant in the defect is covered with a piece of autologous periosteum $(\mathrm{ACl}-\mathrm{P})^{12}$ or using a manufactured membrane of collagen I/III (ACl-C). ${ }^{7}$ In the second generation, after cell expansion in a monolayer, the cells are deposited on a carrier membrane/matrix, obtaining a membrane sown with $\mathrm{MACl}^{\circledR}$ (chondrocytes (Verigen AG, Leverkusen, Germany). ${ }^{17}$ In the third generation of $\mathrm{ACl}$, the chondrocyte culture is deposited on a matrix of hyaluronic acid structured in three dimensions (Hyalograft- ${ }^{\circledR}$, Fidia Advanced Biopolymers, Abano Term, Italy) ${ }^{37-39}$, thus enabling homogeneous distribution of the chondrocytes inside the lesion. Both in the second and in the third generation of chondrocyte culturing systems for autologous implantation, the technical advantages are translated as decrease of complexity and of surgical time. This system can be performed by arthroscopy alone and using fibrin glue for fixation only, avoiding the removal and suturing of the periosteum. $\mathrm{Ne}-$ vertheless the technique that employs the periosteum is being widely used due to its safety and efficacy.

\section{Surgical approach and lesion debridement}

The patient is prepared and habitual anesthetic precautions are taken. A pneumatic tourniquet is positioned on the thigh and inflated after exsanguination of the limb with an Esmarch bandage. A standard parapatellar, medial or lateral incision is made and the knee is opened up by means of mini-arthrotomy. (Figure 3A) After achieving adequate exposure, the lesion should be debrided to remove all unviable tissue. The diseased cartilage surrounding the lesion is removed, the chondral fissures and erosions inside the defect are regularized, and the fibrous tissue present at the base of the lesion is debrided. The aim of this initial preparation of the defect is to obtain a lesion surrounded by healthy 
cartilage and with the base free from blood. If bleeding occurs during this preparation, it is necessary to perform hemostasis, either with a gauze plug with adrenaline, or with fibrin glue. This avoids the migration of fibroblasts or mesenchymal cells from the bone marrow to the interior of the lesion, which compromises the results of the $\mathrm{ACl}$. (Figure 3B)

Once the defect has been prepared, a mold of the lesion should be made using a sheet of aluminum or sterile paper. This mold is used to help remove the periosteum graft in the next stage.

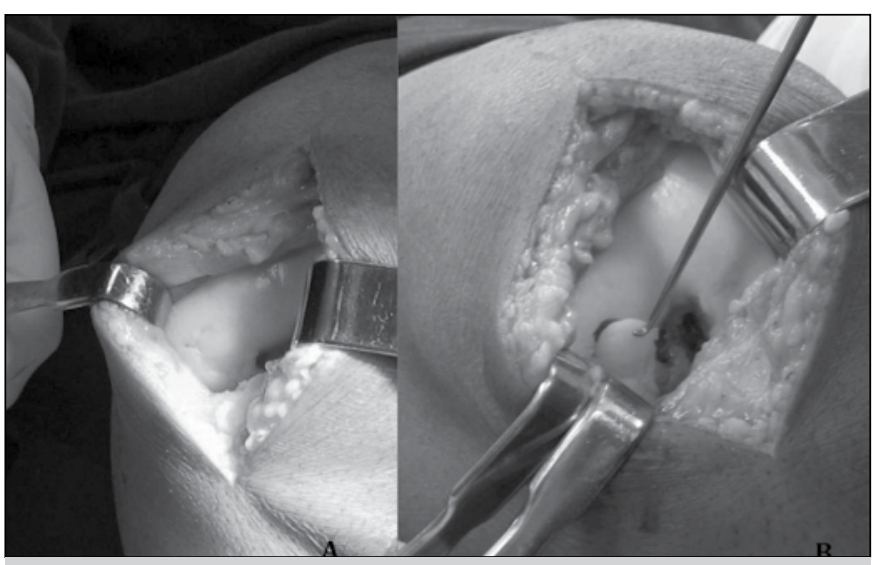

Figure 3. (A) View of complete chondral lesion, in the femoral condyle of the left knee of a soccer player, after medial parapatellar arthrotomy; (B) Regularization and debridement of the fibrous tissue present at the base of the lesion.

\section{Periosteum graft}

The periosteum graft is obtained through an incision over the medial proximal tibia, approximately $4 \mathrm{~cm}$ distally from the medial surface of the tibial tuberosity. (Figure 4) The periosteum is dissected, removing all the fat and fascia on top of it. The lesion mold obtained previously is positioned, and the periosteum is marked out with the addition of $1-2 \mathrm{~mm}$ on the edge. (Figure 3) This precaution is taken as there is a tendency for the periosteum to shrink after harvesting. Then the graft is cut on the mark made, and using a periosteum detacher, the periosteal membrane is removed from the bone. The thinner the membrane, the lower the risk of hypertrophy and fibrillation of the periosteum, besides making it possible to inject a greater volume of chondrocyte concentrate. Graft perforation should be avoided during the harvesting. A mark should also be made on the graft to identify the internal layer of the periosteum.

\section{Suturing of Periosteum Graft and Chondrocyte Implantation}

The internal layer of the periosteum contains chondrogenic cells that, in combination with the implanted chondrocytes, help to produce the repair tissue. This layer, identified earlier, should be positioned facing the bony part of the lesion and anchored with separate stiches of 5-0 or 6-0 Vycril ${ }^{\circledR}$. These stiches should be made with small cutting needles, starting from the outside to the inside in the periosteum and ending by going from inside to outside in the cartilage, with the knot tied on the side of the periosteum, thereby avoiding cutting the cartilage with the thread. These stiches should be spaced $3-4 \mathrm{~mm}$ from each other, and

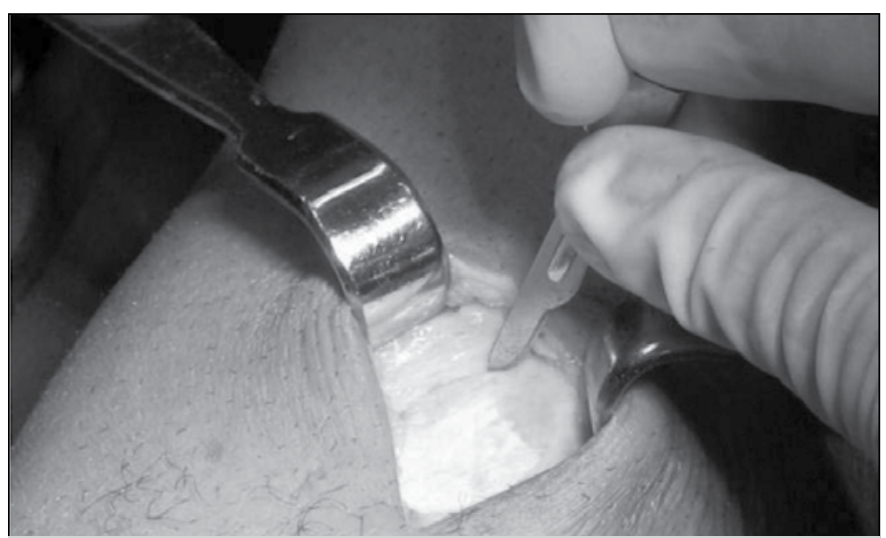

Figure 4. Removal of the periosteum graft from the medial side of the proximal tibia.

the intervals should be sealed with fibrin glue. This is followed by a check for any leakage sites, by slowly injecting saline solution under the periosteum. Having verified the hermetic closure of the lesion, the surgeon should inject the autologous chondrocyte concentrate into the defect. (Figure 5)

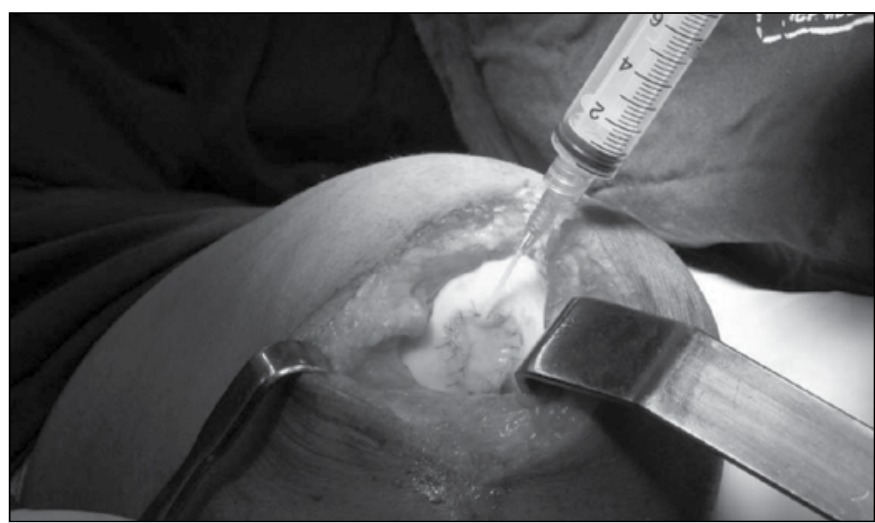

Figure 5. Injection of autologous chondrocyte concentrate under the periosteum plug of the lesion.

\section{PROTECTION OF THE CHONDRAL REPAIR}

The isolated chondral lesion is rarely the only cause of symptoms and dysfunction of patients. These lesions are frequently associated with other knee pathologies. Misalignment of the limb and ligament instability can overload the chondral defect, affecting the result of the chondrocyte transplant. Accordingly, satisfactory clinical results cannot be expected from the cartilage repair methods until the coexisting pathologies are treated and conditions are created to protect the chondral repair.

\section{Misalignment}

If the physical examination or the initial $x$-rays indicate some form of misalignment of the limb, it is necessary to take a panoramic radiograph of the lower limb, including hip and ankle. If the mechanical axis passes through the compartment in which the lesion is located, it is recommended to perform osteotomy to divert the forces of the impaired compartment. ${ }^{40}$ (Figure 6) In the case of large condylar lesions, without misalignment of the limb, the chondral repair should be protected with load diverting 


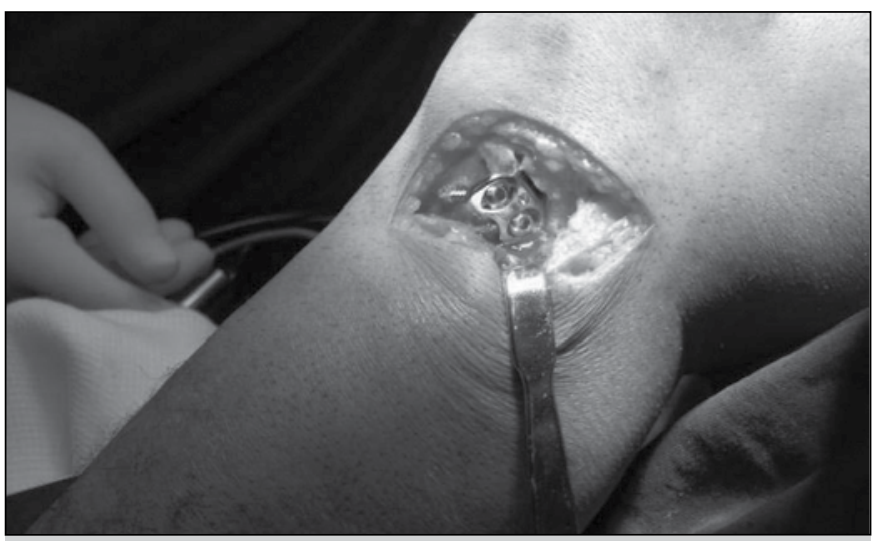

Figure 6. In patients that present the mechanical axis passing through the compartment in which the lesion is located, it is recommended to perform an osteotomy to divert the forces of the impaired compartment

orthosis made to order. Repairs that are not protected can present a good appearance for two years, but overload in the lesion area evolves with tapering and destruction of the repair. ${ }^{2,40}$

\section{Instability}

Ligament instability produces excessive shear force in the knee and this mechanical imbalance damages the repair tissue. If $A C L$ reconstruction is performed concomitantly, the $\mathrm{ACl}$ should only be finished after ACL fixation. Amin et al. ${ }^{3}$ published their experience in the treatment using $\mathrm{ACl}$ in combination with $\mathrm{ACL}$ reconstruction. They report that the combination of the two procedures is viable and that the clinical results of $A C L$ reconstruction are improved when this procedure is associated with $\mathrm{ACl}$.

\section{Meniscal Lesion}

The lack of meniscal protection of the cartilage overloads the chondrocyte transplantation region. Whenever possible, the meniscus should be preserved or repaired. If the patient has undergone total or partial meniscectomy leaving the meniscus without protective function, the possibility of meniscus transplantation should be considered. The meniscal allograft will help reduce the concentration of forces in the compartment involved and will protect the recently formed repair tissue.

When the meniscus transplantation is performed at the same time as the $\mathrm{ACl}$, attention should be paid to a technicality. First of all the meniscal allograft is positioned and fixed, then the $\mathrm{ACl}$ procedure is completed, thus avoiding undesirable manipulations and accidents in the chondrocyte transplantation. ${ }^{25,40}$

\section{Bone Defect}

Superficial bone lesions up to $8 \mathrm{~mm}$ in depth evolve well when treated just with ACl. ${ }^{41}$ Peterson et al. ${ }^{42}$ monitored 58 patients diagnosed with osteochondritis dissecans and treated with $\mathrm{ACl}$ over an average period of 5.6 years. $91 \%$ of the patients had good or excellent clinical results, some with bone defect above $10 \mathrm{~mm}$ in depth. However, the current recommendation is to graft bone defects above $8 \mathrm{~mm} .{ }^{43}$ The bone graft can be performed at the time of the arthroscopic evaluation or of the cartilage biopsy. Another option is to perform the procedure all at once by means of the "sandwich" technique. In this procedure, the bone defect is filled with spongy bone graft up to the height of the subchondral bone and covered with a piece of periosteum at this level. A second piece of periosteum is fixed at the top of the cartilage, then the chondrocyte suspension is injected between the two periosteum layers. ${ }^{25}$

\section{REHABILITATION}

The basic principles for success of the postoperative ACl rehabilitation program should be focused on protection of the graft, joint mobilization exercises, muscle strengthening and load progression. Rehabilitation should be based on the state and needs of the patient, on the lesion size and location and on whether there has been any surgical procedure in association with the $\mathrm{ACl}^{4,38}$ During the initial postoperative period it is mandatory to protect the repair tissue against excessive intra-articular forces, mainly avoiding rotating movements and friction on the repair. The CPM (continuous passive motion) machine usually starts on the first postoperative day and continues while the patient remains in hospital (2 to 3 days). The load is gradually increased and the patient starts to take their first steps. The isometric strengthening of the quadriceps and of the flexors is introduced early in the rehabilitation program and should progressively advance to exercises against resistance. ${ }^{44}$

Some closed chain exercises are introduced in the program in the $3^{\text {rd }}$ postoperative week. Open chain exercises are started in the $2^{\text {nd }}$ postoperative month. It is recommended to start running eight months after surgery and high impact activities 12 months after surgery.

The rehabilitation of femoropatellar lesions requires special considerations. Pressure in the femoropatellar joint reaches its peak between $40^{\circ}$ and $70^{\circ}$ of knee flexion and these degrees of range of motion (ROM) should be avoided until the repair tissue is mature enough to bear the friction force. CPM should be used and open chain exercises are allowed from the $3^{\text {rd }}$ postoperative month of the patellar or trochlear lesion repair. If the lesion is large, the use of a brace can be considered for load alleviation. ${ }^{45}$

\section{INTERNATIONAL EXPERIENCE}

The first clinical study published using $\mathrm{ACl}$ for the treatment of chondral lesions was in 1994, in which 23 patients were included. ${ }^{12}$ Since then, thousands of patients have been treated by this technique and various authors have published their results around the world.

In patients with small and acute bone lesion, $\mathrm{ACl}$ is generally applied after other techniques have been tried and failed after 6 months. $\mathrm{ACl}$ and osteochondral transplantation should be used in large acute lesions $\left(>3 \mathrm{~cm}^{2}\right)$, precisely because for these large lesions, it is hard to obtain adequate coverage using other techniques. ${ }^{9}$ (Table 1 )

Table 1. Recommendations among the various alternatives for biological reconstruction of the joint surface. ${ }^{9}$

\begin{tabular}{c|c|c|c}
\hline & Microfractures & OCT & ACl \\
\hline Children and Adolescents & +++ & - & - \\
\hline $1-2 \mathrm{~cm}^{2}$ lesion & +++ & ++ & - \\
\hline $1-4 \mathrm{~cm}^{2}$ lesion & + & +++ & ++ \\
\hline $3-14 \mathrm{~cm}^{2}$ lesion & - & + & +++
\end{tabular}


In a study that evaluated 244 patients, with clinical follow-up for 2 to 10 years, noteworthy subjective and objective clinical improvements were observed when $\mathrm{ACl}$ treatment was used. A large portion of these patients had femoral condyle lesions or osteochondritis dissecans. There was a high percentage of good and excellent results (84-90\%) among the patients with isolated femoral condyle lesions. On the other hand, the rate was low (mean of $74 \%$ ) among those with other types of lesion (patellar, trochlear and multiple lesions). ${ }^{40}$

To study the long-term durability of $\mathrm{ACl}, 61$ patients were monitored for 5-11 years (mean of 7.4 years) after surgery. After two years, 50 of the 61 patients had good or excellent results, and after 5-11 years of evolution, 51 of the 61 patients were graded as good/excellent results. The total failure rate was 16\% (10/61 patients), among which all the ACl failures occurred in the first two years. Thus, the high percentage of patients with good/excellent results in the first two years remained well for a long period of postoperative follow-up..$^{40}$

Many authors have compared the $\mathrm{ACl}$ technique with other cartilage repair procedures, yet only a few of them were able to design studies with a relevant degree of clinical evidence. Based on the systematic review of literature published in 2006 by Wasiak et al. ${ }^{2}$ in the Cochrane Database Systematic Review, we selected some of these prospective, randomized clinical studies.

\section{$\mathrm{ACl}$ versus Microfractures}

Knutsen et al. ${ }^{46}$ studied 80 patients with symptomatic cartilage lesion of the femoral condyles requiring repair, measuring 2-10 $\mathrm{cm}^{2}$. The patients were randomized between two groups treated with $\mathrm{ACl}$ and microfractures and followed up for 12 and 24 months. Based on the SF-36 questionnaire applied two years after surgery, the microfractures group presented a significant improvement in comparison to the $\mathrm{ACl}$ group $(p=0.004)$. Although both groups presented improvements of the Lysholm score and of the Visual Analogue Scale, there was no statistical difference between them. Neither was there any significant difference between the two groups when comparing the quality of the repair tissue in the histological evaluation and its association with the clinical results.

\section{$\mathrm{ACl}$ versus OCT (Mosaicplasty)}

Horas et al. ${ }^{47}$ conducted a quasi-randomized, prospective clinical study ( $<80 \%$ of follow-up) with 40 patients to compare the results of the $\mathrm{ACl}$ and OCT techniques for the treatment of complete chondral defects (mean of $3.75 \mathrm{~cm}^{2}$ ). Both treatments reduced the patients' symptoms, but a statistically significant difference was reported in the Lysholm score at 6, 12 and 24 months, which favored the OCT group. However, the other indices used for clinical evaluation by the study (Meyers score and Tegner score) did not present significant difference in comparing the two techniques. Bentley et al. ${ }^{48}$ published a randomized and controlled clinical study with 100 patients (58 patients treated with $\mathrm{ACl}$ and 42 with OCT). The majority were posttraumatic lesions with chondral defect size averaging $4.76 \mathrm{~cm}^{2}$. After a mean follow-up period of 19 months (12-26 months), it was shown that $88 \%$ of the patients treated with $\mathrm{ACl}$ and $69 \%$ treated with OCT presented good or excellent clinical results, according to a clinical and functional evaluation $(p<0.05)$. The arthroscopic evaluation, carried out after one year of treatment, showed that $82 \%$ of the patients treated with $\mathrm{ACl}$ and $34 \%$ of the OCT group presented excellent or good quality of the joint repair $(p<0.001)$.

\section{$\mathrm{MACl}$ versus Microfractures}

Basad et al. ${ }^{49}$ studied 46 patients with post-traumatic chondral lesions (mean defect of 2-10 $\mathrm{cm}^{2}$ ) and compared treatment through $\mathrm{MACl}$ or by microfractures. After 2 years of follow-up, the $\mathrm{MACl}$ group presented better results based on the Lysholm score $(p=0.049)$ and the Meyer's index $(p=0.024)$. However, the differences based on the Tegner index $(p=0.064)$ and ICRS score $(p=0.32)$ were not significant. In the same study, Basad performed a MR two years after surgery and demonstrated complete equalization of the sign between the regenerated tissue and the normal cartilage surrounding the repair in the $\mathrm{MACl}$ group. In the microfractures group, the sign obtained in the repair was different when compared with the normal cartilage.

\section{$M A C I$ versus $A C I$}

Bartlett et al. ${ }^{14}$ performed a prospective, randomized comparison between $\mathrm{ACl}$ and $\mathrm{MACl}$ for the treatment of symptomatic chondral defects of 91 knees of patients (44 received $\mathrm{ACl}$ and $47 \mathrm{MACl}$ ) and found similar outcomes in the two groups. There was an improvement in the clinical evaluation indexes (Cincinnati score) in both treatment groups, without any statistical difference between them. Likewise, both treatments showed excellent and good results after the arthroscopic evaluation of ICRS (79.2\% in the $\mathrm{ACl}$ group and $66.6 \%$ of $\mathrm{MACl}, \mathrm{p}=0.3)$. There was no statistical difference between the two groups after the histological evaluation (proportion of fibrocartilage mixed with the hyaline cartilage and hypertrophy rate of the repair) either.

\section{OUTLOOK}

New generations of $\mathrm{ACI}$

$\mathrm{MACl}^{\circledR}$ (Verigen AG, Leverkusen, Germany) ${ }^{17}$ and Hyalograft-C ${ }^{\circledR}$ (Fidia Advanced Biopolymers, Abano Term, Italy) ${ }^{38,39}$ are examples of the new generation of chondrocyte implantations. $\mathrm{MACl}^{\circledR}$ uses a matrix of collagen type $\mathrm{I} / \mathrm{III}$ matrix to sow chondrocytes in a double layer. Hyalograft- $C^{\circledR}$ uses a 3-D matrix of hyaluronic acid that acts as a support for the growth of chondrocytes in vitro. These matrixes containing the chondrocytes are implanted on the chondral lesion and attached with fibrin glue. In this manner, periosteum grafts and their suturing onto healthy cartilage are not necessary. These techniques were developed in an attempt to resolve some of the more common problems indicated by the $\mathrm{ACl}^{40}$ technique: periosteum hypertrophy, which is a source of complaints about localized pain among some patients.

\section{CONCLUSIONS}

Autologous chondrocyte transplantation has become an alternative for treating complete chondral lesions since when the first case series were published, and several authors have reported excellent and good results in the use of this surgical technique. Tissue engineering has developed new methodologies and has presented improvements and refinements of the original $\mathrm{ACl}$ technique. However, all this technology entails a high cost and, moreover, there is not yet sufficient evidence in literature to affirm that $\mathrm{ACl}$ is superior to the other complete chondral defect treatment strategies. New studies are required to obtain further information that can help define the conduct for chondral lesions, pursuing the goal of better quality of life for patients. 


\section{REFERENCES}

1. Buckwalter JA. Articular cartilage: injuries and potential for healing. J Orthop Sports Phys Ther. 1998;28:192-202.

2. Wasiak J, Clar C, Villanueva E. Autologous cartilage implantation for full thickness articular cartilage defects of the knee. Cochrane Database Syst Rev. 2006;3:CD003323.

3. D'Lima DD, Hashimoto S, Chen PC, Lotz MK, Colwell CW Jr. Cartilage injury induces chondrocyte apoptosis. J Bone Joint Surg Am. 2001;83(Suppl 2):19-21.

4. Borrelli J Jr, Tinsley K, Ricci WM, Burns M, Karl IE, Hotchkiss R. Induction of chondrocyte apoptosis following impact load. J Orthop Trauma. 2003;17:635-41.

5. Buckwalter JA, Mankin HJ. Articular cartilage: degeneration and osteoarthritis, repair, regeneration, and transplantation. Instr Course Lect. 1998;47:487-504

6. Buckwalter JA, Mankin HJ. Articular cartilage: tissue design and chondrocytematrix interactions. Instr Course Lect. 1998;47:477-86.

7. Rezende MU, Gurgel HM, Vilaça Junior PR, Kuroba RK, Lopes AS, Phillipi RZ, Hernandez AJ. Diacerhein versus glucosamine in a rat model of osteoarthritis. Clinics (Sao Paulo) 2006;61:461-6.

8. Scopp JM, Mandelbaum BR. A treatment algorithm for the management of articular cartilage defects. Orthop Clin North Am. 2005;36:419-26.

9. Fritz J, Janssen P, Gaissmaier C, Schewe B, Weise K. Articular cartilage defects in the knee--basics, therapies and results. Injury. 2008;39(Suppl 1):S50-7.

10. Zhang W, Moskowitz RW, Nuki G, Abramson S, Altman RD, Arden N, et al OARSI recommendations for the management of hip and knee osteoarthritis, Part II: OARSI evidence-based, expert consensus guidelines. Osteoarthritis Cartilage. 2008;16:137-62

11. Mithoefer K, Williams RJ 3rd, Warren RF, Potter HG, Spock CR, Jones EC, et al. Chondral resurfacing of articular cartilage defects in the knee with the microfracture technique. Surgical technique. J Bone Joint Surg Am. 2006;88(Suppl $1 \mathrm{Pt}$ 2):294-304.

12. Brittberg M, Lindahl A, Nilsson A, Ohlsson C, Isaksson O, Peterson L. Treatment of deep cartilage defects in the knee with autologous chondrocyte transplantation. N Engl J Med. 1994;331:889-95.

13. Behrens P, Ehlers EM, Kochermann KU, Rohwedel J, Russlies M, Plotz W. [New therapy procedure for localized cartilage defects. Encouraging results with autologous chondrocyte implantation]. MMW Fortschr Med. 1999;141:49-51.

14. Bartlett W, Skinner JA, Gooding CR, Carrington RW, Flanagan AM, Briggs TW, et al. Autologous chondrocyte implantation versus matrix-induced autologous chondrocyte implantation for osteochondral defects of the knee: a prospective, randomised study. J Bone Joint Surg Br. 2005;87:640-5.

15. Gooding CR, Bartlett W, Bentley G, Skinner JA, Carrington R, Flanagan A A prospective, randomised study comparing two techniques of autologous chondrocyte implantation for osteochondral defects in the knee: Periosteum covered versus type 1/III collagen covered. Knee. 2006;13:203-10.

16. Lu Y, Dhanaraj S, Wang Z, Bradley DM, Bowman SM, Cole BJ, et al. Minced cartilage without cell culture serves as an effective intraoperative cell source for cartilage repair. J Orthop Res. 2006;24:1261-70.

17. Cherubino P, Grassi FA, Bulgheroni P, Ronga M. Autologous chondrocyte implantation using a bilayer collagen membrane: a preliminary report. J Orthop Surg (Hong Kong). 2003;11:10-5.

18. Akimau P, Bhosale A, Harrison PE, Roberts S, McCall IW, Richardson JB, et al. Autologous chondrocyte implantation with bone grafting for osteochondra defect due to posttraumatic osteonecrosis of the hip--a case report. Acta Orthop. 2006;77:333-6.

19. Giannini S, Buda R, Grigolo B, Vannini F. Autologous chondrocyte transplantation in osteochondral lesions of the ankle joint. Foot Ankle Int. 2001;22:513-7.

20. Koulalis D, Schultz W, Psychogios B, Papagelopoulos PJ. Articular reconstruction of osteochondral defects of the talus through autologous chondrocyte transplantation. Orthopedics. 2004;27:559-61.

21. Petersen L, Brittberg M, Lindahl A. Autologous chondrocyte transplantation of the ankle. Foot Ankle Clin. 2003;8:291-303

22. Romeo AA, Cole BJ, Mazzocca AD, Fox JA, Freeman KB, Joy E. Autologous chondrocyte repair of an articular defect in the humeral head. Arthroscopy. 2002; 18:925-9.

23. Outerbridge R. The etiology of chondromalacia patellae. J Bone Joint Surg Br. 1961;43:752

24. International Cartilage Repair Society. Available from: www.cartilage.org Accessed at 2005

25. Brittberg M. Autologous chondrocyte implantation--technique and long-term follow-up. Injury. 2008;39(Suppl 1):S40-9.

26. Petersen L. International experience with autologous chondrocyte transplantation In: Scott N, Insall J, editors. Insall \& Scott - Surgery of the knee. 4th ed New York: Elsevier; 2006.

27. Rosenberg TD, Paulos LE, Parker RD, Coward DB, Scott SM. The forty-fivedegree posteroanterior flexion weight-bearing radiograph of the knee. J Bone Joint Surg Am. 1988;70:1479-83.

28. Trattnig S, Millington SA, Szomolanyi P, Marlovits S. MR imaging of osteochondral

Acta Ortop Bras. 2011;19(4): 219-25 grafts and autologous chondrocyte implantation. Eur Radiol. 2007;17:103-18.

29. Tallheden T, van der Lee J, Brantsing C, Mansson JE, Sjogren-Jansson E, Lindahl A. Human serum for culture of articular chondrocytes. Cell Transplant. 2005; 14:469-79

30. Archer CW, McDowell J, Bayliss MT, Stephens MD, Bentley G. Phenotypic modulation in sub-populations of human articular chondrocytes in vitro. J Cell Sci. 1990;97( Pt 2):361-71.

31. Bujia J, Sittinger M, Pitzke P, Wilmes E, Hammer C. Synthesis of human cartilage using organotypic cell culture. ORL J Otorhinolaryngol Relat Spec. 1993;55:347-51.

32. Folkman J, Moscona A. Role of cell shape in growth control. Nature. 1978;273:345-9

33. Shapiro F, Koide S, Glimcher MJ. Cell origin and differentiation in the repair of full-thickness defects of articular cartilage. J Bone Joint Surg Am. 1993;75:532-53

34. Gavenis K, Schmidt-Rohlfing B, Mueller-Rath R, Andereya S, Schneider U. In vitro comparison of six different matrix systems for the cultivation of human chondrocytes. In Vitro Cell Dev Biol Anim. 2006;42:159-67.

35. Martin I, Suetterlin R, Baschong W, Heberer M, Vunjak-Novakovic G, Freed LE. Enhanced cartilage tissue engineering by sequential exposure of chondrocytes to FGF-2 during 2D expansion and BMP-2 during 3D cultivation. J Cell Biochem. 2001;83:121-8.

36. Glowacki J, Trepman E, Folkman J. Cell shape and phenotypic expression in chondrocytes. Proc Soc Exp Biol Med. 1983;172:93-8.

37. Gobbi A, Kon E, Berruto M, Francisco R, Filardo G, Marcacci M. Patellofemoral full-thickness chondral defects treated with Hyalograft-C: a clinical, arthroscopic, and histologic review. Am J Sports Med. 2006;34:1763-73.

38. Grigolo B, Lisignoli G, Piacentini A, Fiorini M, Gobbi P, Mazzotti G, et al. Evidence for redifferentiation of human chondrocytes grown on a hyaluronanbased biomaterial (HYAff 11): molecular, immunohistochemical and ultrastructural analysis. Biomaterials. 2002;23:1187-95

39. Marcacci M, Berruto M, Brocchetta D, Delcogliano A, Ghinelli D, Gobbi A, et al. Articular cartilage engineering with Hyalograft C: 3-year clinical results. Clin Orthop Relat Res. 2005:96-105.

40. Brittberg M, Peterson L, Sjogren-Jansson E, Tallheden T, Lindahl A. Articular cartilage engineering with autologous chondrocyte transplantation. A review of recent developments. J Bone Joint Surg Am. 2003;85(Suppl 3):109-15.

41. Amin AA, Bartlett W, Gooding CR, Sood M, Skinner JA, Carrington RW, et al The use of autologous chondrocyte implantation following and combined with anterior cruciate ligament reconstruction. Int Orthop. 2006; 30: 48-53.

42. Peterson L, Minas T, Brittberg M, Lindahl A. Treatment of osteochondritis dissecans of the knee with autologous chondrocyte transplantation: results at two to ten years. J Bone Joint Surg Am. 2003;85(Suppl 2):17-24.

43. Marcacci M, Zaffagnini S, Kon E, Visani A, lacono F, Loreti I. Arthroscopic autologous chondrocyte transplantation: technical note. Knee Surg Sports Traumatol Arthrosc. 2002;10:154-9.

44. Reinold MM, Wilk KE, Macrina LC, Dugas JR, Cain EL. Current concepts in the rehabilitation following articular cartilage repair procedures in the knee. $J$ Orthop Sports Phys Ther. 2006;36:774-94.

45. Gomoll AH, Minas T, Farr J, Cole BJ. Treatment of chondral defects in the patellofemoral joint. J Knee Surg. 2006;19:285-95.

46. Knutsen G, Engebretsen L, Ludvigsen TC, Drogset JO, Grøntvedt T, Solheim $\mathrm{E}$, et al. Autologous chondrocyte implantation compared with microfracture in the knee. A randomized trial. J Bone Joint Surg Am. 2004;86:455-64.

47. Horas U, Pelinkovic D, Herr G, Aigner T, Schnettler R. Autologous chondrocyte implantation and osteochondral cylinder transplantation in cartilage repair of the knee joint. A prospective, comparative trial. J Bone Joint Surg Am. 2003;85:185-92.

48. Bentley G, Biant LC, Carrington RW, Akmal M, Goldberg A, Williams AM, et al. A prospective, randomised comparison of autologous chondrocyte implantation versus mosaicplasty for osteochondral defects in the knee. J Bone Joint Surg Br. 2003;85:223-30.

49. Basad E, Stürz H, Steinmeyer J. Treatment of chondral defects with MACl or microfracture. First results of a comparative clinical study. Orthopädische Praxis. 2004;40:6-10. 